\title{
Kinematics modeling and simulation analysis of sugarcane harvester hybrid drive collection mechanism with three degrees of freedom
}

\author{
Bin Xue ${ }^{1}$, Yuchen Pan' ${ }^{2}$ Xuepeng Yuan ${ }^{3}$, Qu Yang ${ }^{4}$ \\ 1,2,3,4Beibu Gulf University, School of Mechanical and Naval Architecture and Marine Engineering, \\ Qinzhou, 535011, China \\ ${ }^{1}$ South China University of Technology, School of Mechanical and Automotive Engineering, \\ Guang Zhou, 510641, China \\ ${ }^{2,4}$ Corresponding author

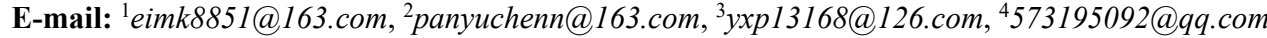

Received 18 December 2019; accepted 13 January 2020 DOI https://doi.org/10.21595/vp.2020.21242

Check for updates

Copyright $\mathbb{C} 2020$ Bin Xin, et al. This is an open access article distributed under the Creative Commons Attribution License, which permits unrestricted use, distribution, and reproduction in any medium, provided the original work is properly cited.

\begin{abstract}
In view of the problems existed of sugarcane harvester in China, the paper analyzes the types and characteristics of the existing sugarcane collection mechanism. A new type of three degree of freedom sugarcane harvester hybrid drive collection mechanism was designed in three dimensions. The geometric model of the new configuration related components and the overall assembly was established. And imported into the ADAMS simulation software. After the simulation, the working point and the force curve of the component node were output and analyzed. In order to obtain the motion law of the new three-degree-of-freedom stacking mechanism, verify the correctness of the theoretical model, and provide reference for the in-depth research and prototype trial production of the stacking mechanism in the future.
\end{abstract}

Keywords: hybrid drive, sugarcane harvester, cane plant, simulation analysis.

\section{Introduction}

Throughout the development of the world sugar cane industry $[1,2]$, the regions of the Americas and Australia [3] have flat terrain due to sugarcane planting. Most of them are mostly large-scale sugarcane contiguous planting pattern, which have basically achieved planting, management, and the whole process of mechanization control is harvested, but the cost of introduction is higher due to the problem of topography and landform in China, which caused the sugarcane harvesters cannot be widely used in China. The development history of sugarcane harvesters in China is relatively slow, and there are few researches on sugarcane harvesters. From the specific point of view, the existing sugarcane harvesters have the imperfections in the collection of sugarcane efficiency and quality after harvesting, such as the existence of sugarcane collection. Falling to the ground or unloading position is not conducive to the sugarcane transportation problem of harvesting, which greatly affects the efficiency of sugarcane harvesters and the quality of sugarcane, which seriously restricts the development of agricultural economy. Therefore, designing a kind of maneuvering device with better maneuverability is of great significance to mechanization of sugarcane harvesting in China.

\section{The design of the sugarcane collection mechanism}

According to different planting terrains, different types of cane collecting mechanisms such as one-side dumping stacking mechanism, double-side dumping stacking mechanism and triangular stacking mechanism have been designed $[4,5]$, however, it is found that flexibility of the sugarcane collection mechanism is poor. Due to the irregularity of planting fields during the sugarcane collection process, caused sugarcane collection mechanism has not been widely used. Therefore, it is necessary to develop a flexible sugarcane collection mechanism, reducing the 
workload of sugar cane collection and costs. The design of the sugarcane collection mechanism should meet the size requirements and meet various irregular fields of different planting terrain $[6,7]$. Based on previous analysis and research, the sugarcane harvester hybrid drive collection mechanism with three degrees of freedom was designed as shown in Fig. 1.
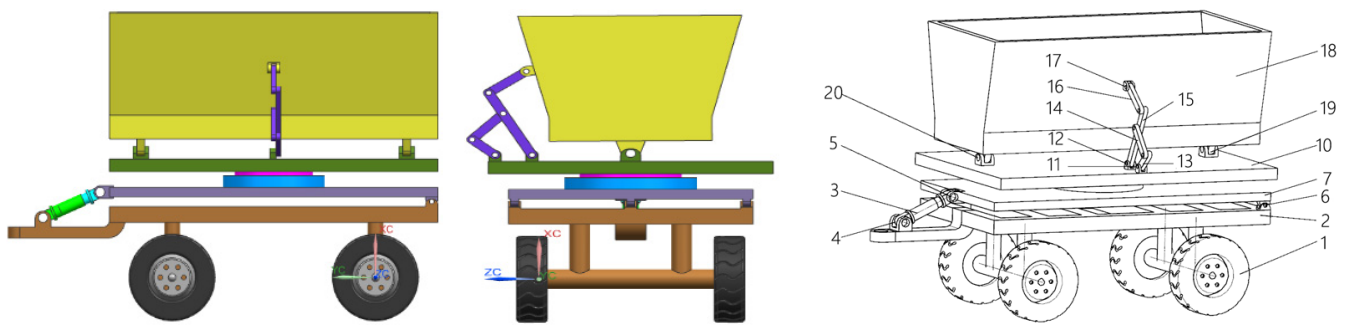

Fig. 1. Model of sugarcane collecting device

\section{Kinematics analysis of the model}

After the model sugarcane collection mechanism and assembly of the new cane plant is completed, the ADAMS software [8] can be imported and the constraints imposed as shown in Fig. 2.
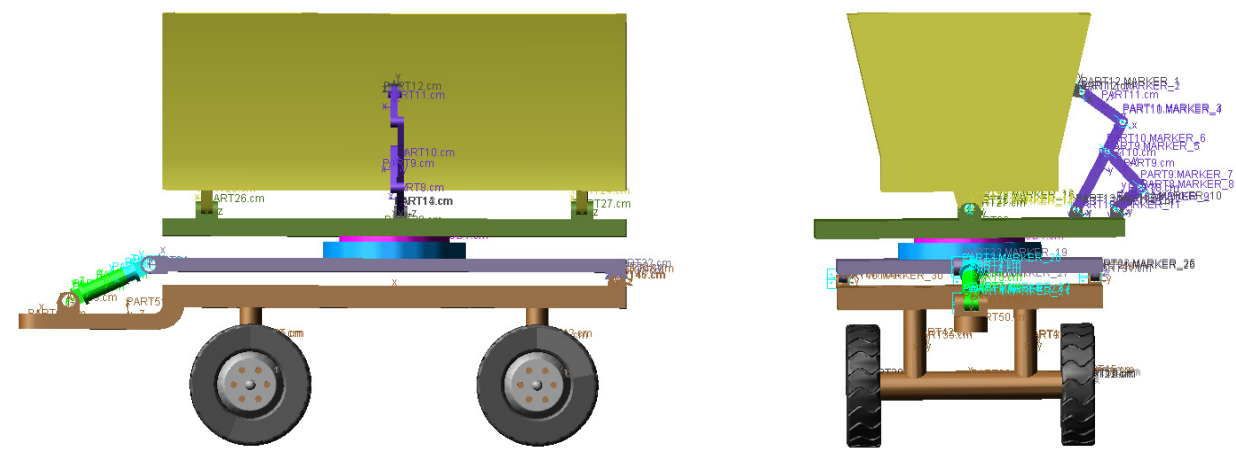

Fig. 2. Application of individual component constraints

The simulation time of setting up the sugarcane collection mechanism is $24 \mathrm{~s}$, and according to the movement trajectory requirements of the sugarcane operation, the trajectory of the various aspects of the sugarcane mechanism in the post-processing of ADAMS is shown in Fig. 3. It can be seen from that the movement law of the sugarcane mechanism in the backward unloading, rotary motion and side unloading direction is close to the design requirements of the new sugarcane mechanism, and the work corresponding to the current use of the sugarcane mechanism can be basically completed.

\section{Mechanical simulation analysis}

A dynamic load is applied to simulate the dynamic change of the force on each bar when the sugarcane collector collects more and more sugarcane. When a dynamic load is applied to the sugarcane compartment, the pressure increased from $0 \mathrm{~N}$ to $10000 \mathrm{~N}$ in $0 \mathrm{~s}-4 \mathrm{~s}$, and then from $20 \mathrm{~s}$ on, the pressure decreases gradually. After $24 \mathrm{~s}$, the pressure is $0 \mathrm{~N}$, which is equivalent to the unloading of sugarcane. Gravity is in the negative $X$ direction. The stress diagram of each component is shown in Fig. 4 and Fig. 5.

Fig. 4(a) shows that the force in $X$ direction gradually increases to $5000 \mathrm{~N}$ and in $Y$ direction gradually increases to $10000 \mathrm{~N}$ due to the influence of dynamic load pressure on the sugarcane compartment during 0 to $4 \mathrm{~s}$. In the lifting process of $4 \mathrm{~s}$ to $8 \mathrm{~s}$, the lifting force decreases with the 
increase of the lifting angle, so the driving force provided by the hydraulic drive device should be at least 1.2 times of the total gravity of the collected sugarcane, the sugarcane collecting chamber and the rotary mechanism. The force on the slewing mechanism is shown in Fig. 4(b). In $0 \mathrm{~s}-4 \mathrm{~s}$, the supporting force of the rotary mechanism gradually increases to $10000 \mathrm{~N}$. In $4 \mathrm{~s}-8 \mathrm{~s}$, due to the influence of the lifting and contraction of the hydraulic cylinder, the sugarcane compartment has a certain up and down tilt angle. The rotary mechanism should apply a certain torque to counteract the torque generated by the tilted sugarcane compartment. In $12 \mathrm{~s}-16 \mathrm{~s}$, the rotating mechanism rotates 90 degrees clockwise, and in $16-20 \mathrm{~s}$, the rotating mechanism rotates 90 degrees anticlockwise, and the torque is shown in the red line in the figure. It can be seen from the torque change of the driving mechanism in the figure that the rotating mechanism needs enough instantaneous force to increase the rotating force when driving. Considering the harsh working environment, it is required that the slewing mechanism bracket, transmission mechanism, reducer and slewing motor have stable and good dynamic performance.
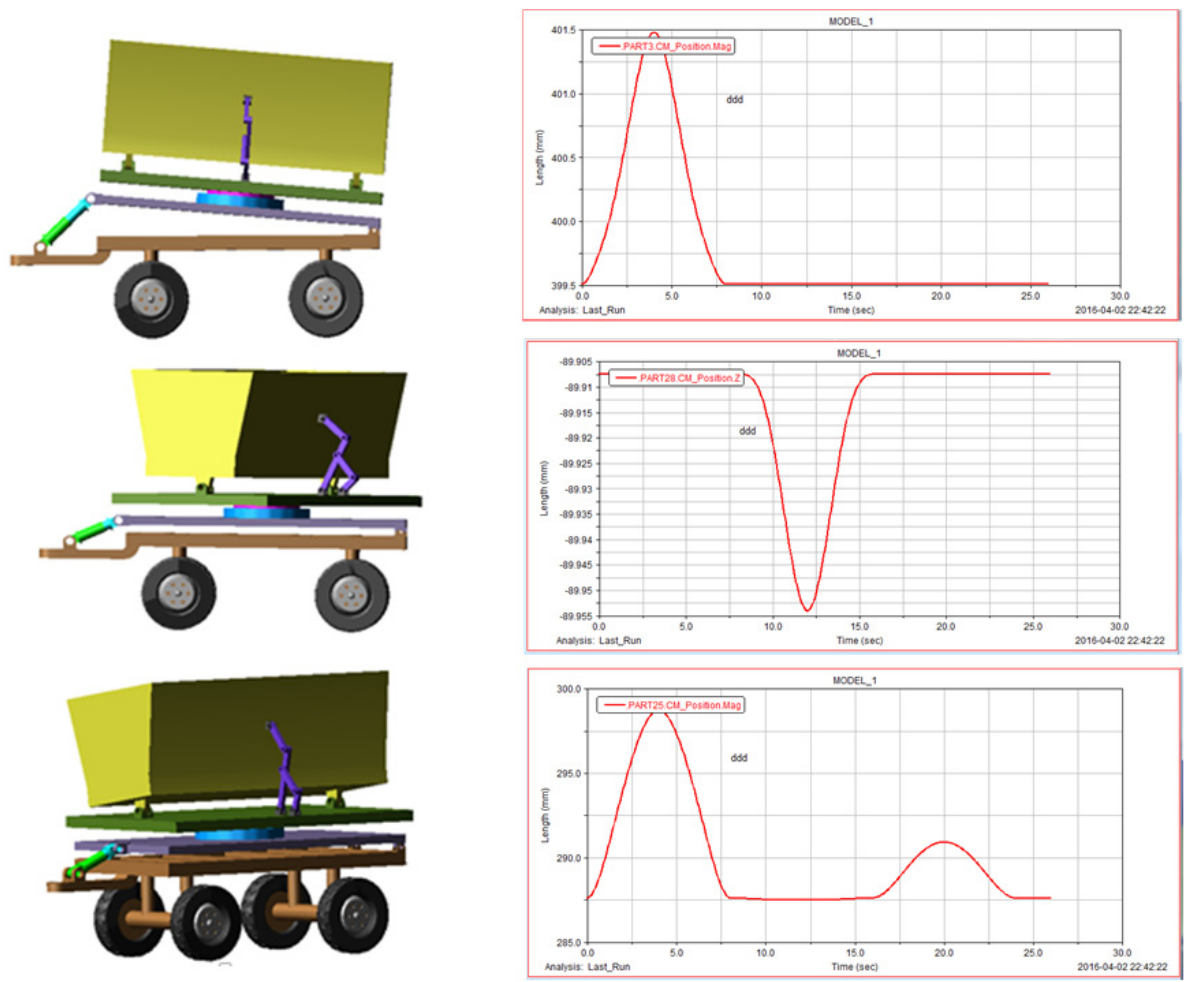

Fig. 3. Model of sugarcane collecting device

Connecting rod 13 is the driving member and connecting rod 14, connecting rod 15 and connecting rod 16 are the driven members. It can be seen in Fig. 5 that in $0 \mathrm{~s}-20 \mathrm{~s}$, since the driving rod 13 is not driven and the sugarcane compartment does not tilt left and right, the driving torques of connecting rod 14, connecting rod 15 and connecting rod 16 are basically 0 , and the connecting rod is only subject to the pressure of the sugarcane compartment; In $20 \mathrm{~s}-24 \mathrm{~s}$, the driving rod 13 rotates a certain angle anticlockwise, the moment and force of each rod gradually increase, so that the sugarcane compartment inclines, at the same time, the sugarcane compartment begins to unload sugarcane, and the pressure is gradually reduced. In the process of dynamic load change, the force and moment change trend of each rod node is basically the same, there is not too big mutation, the link structure is stable, and the simulation results are in line with the force situation of the sugarcane collecting mechanism. 


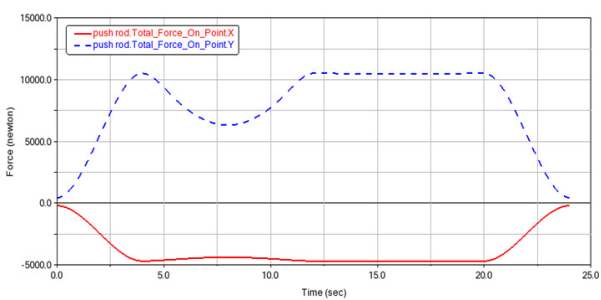

a)

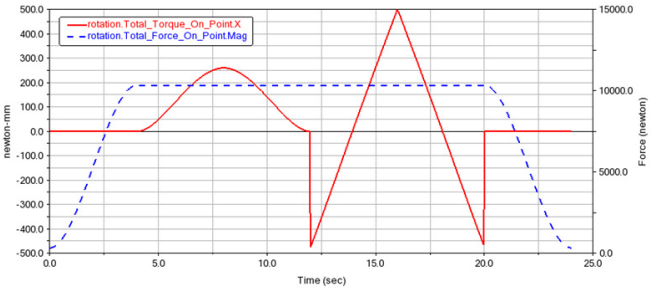

b)

Fig. 4. Force analysis of connecting rods
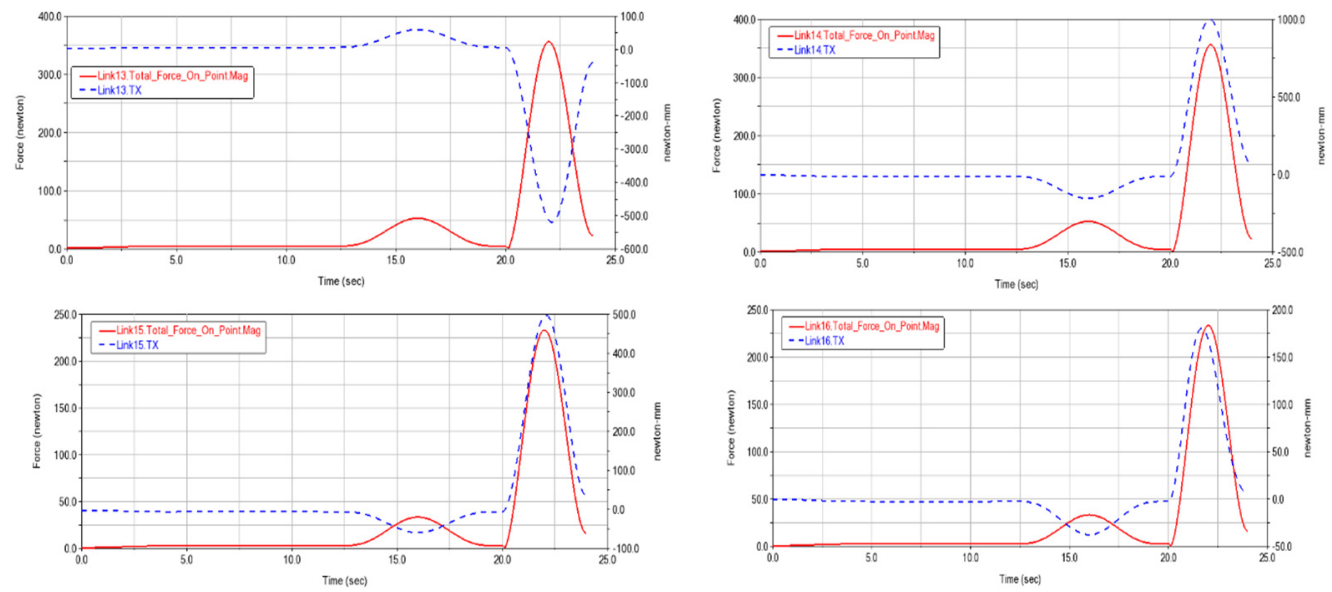

Fig. 5. Force analysis of connecting rods

\section{Conclusions}

This paper analyzes the problems existing of the sugarcane harvester collecting sugarcane plant at home and abroad, and uses the multi-freedom theory of mechanism to design a three-degree-of-freedom hybrid drive mechanism sugarcane harvester collecting sugarcane device, using UG software modeling, and designing by ADAMS simulation technology. The simulation of the sugarcane plant was carried out. The analysis of the working conditions and the stress results of the sugarcane showed that the designed sugarcane device can meet the requirements of use, and the prototype of the prototype did not provide technical support.

\section{Acknowledgements}

The authors acknowledge financial support from the Guangxi Natural Science Foundation (Grant No. 2016GXNSFBA380214), the National Natural Science Foundation of China (Grant No. 51465006) Guangxi Colleges and Universities Key Laboratory Main Subject of Coastal Mechanical Equipment Design, Manufacturing and Control (Grant No. GXLH2014ZD-01, GXLH2016ZD-03).

\section{References}

[1] Suryawanshi V., Thakur S. S., Sharma A. Performance evaluation of experimental self-propelled double row sugarcane harvester. Agricultural Mechanization in Asia, Africa and Latin America, Vol. 45, Issue 2, 2014, p. 48-56.

[2] Gupta C. P., Lwin L., Kiatiwat T. Development of a self-propelled single-axle sugarcane harvester. Applied Engineering in Agriculture, Vol. 12, Issue 4, 1996, p. 427-434. 
[3] Xie L., Wang J., Cheng S., et al. Performance evaluation of a chopper system for sugarcane harvester. SugarTech, Vol. 21, Issue 5, 2019, p. 825-837.

[4] Lv H., Zhang Z., Nong H. The structural design in the new collecting device of sugarcane and the finite element analysis. Journal of Agricultural Mechanization Research, Vol. 32, Issue 4, 2010, p. 60-64.

[5] Huang Y., Wang X., Yin K. Design and experiments of buds-injury-prevention system based on induction-counting in sugarcane-seeds cutting. Transactions of the Chinese Society of Agricultural Engineering, Vol. 31, Issue 18, 2015, p. 41-47.

[6] Yoshiaki Shinzato, Kazumi Uehara, Masami Ueno Adaptability of small-sized sugarcane harvesters in Okinawa. Engineering in Agriculture, Environment and food, Vol. 8, Issue 4, 2015, p. 207-211.

[7] Borpit Tangwongkit Development of Walk-type Sugar Cane Harvester. Kasetsart University, Thailand, 1995.

[8] ADAMS/AutoFlex, MSC. Software Corporation, 2004. 